\title{
Utilization of Polyarylates Having Chemically Introduced Diazonaphthoquinone Structure for Reaction Development Patterning
}

\author{
Toshiyuki Oyama*, Nozomi Shimada and Akio Takahashi \\ Department of Advanced Materials Chemistry, \\ Faculty of Engineering, Yokohama National University \\ 79-5 Tokiwadai, Hodogaya-ku, Yokohama 240-8501, Japan \\ Tel/Fax: +81-45-339-3961,E-mail:oyama1@ynu.ac.jp
}

\begin{abstract}
Polyarylates containing diazonaphthoquinone (DNQ) structure as a photosensitive group in their chains (DNQ-introduced PArs (DPArs)) were synthesized by solution polycondensation using a DNQ having bisphenol structure (BADNQ1) as a diol monomer. Reaction development patterning (RDP) of the DPAr films afforded fine positive-tone patterns in shorter development time and higher resolution than that of the PAr film containing DNQ as an external photosensitive agent. It was also revealed that DPArs could be used as high-molecular-weight photosensitive agents and RDP-based pattern formation using the PAr/DPAr films was achieved in shorter development time and higher resolution than that using the PAr film containing low-molecular-weight DNQ. In addition, the PAr/DPAr film showed higher thermal and mechanical properties than the PAr/DNQ film. Furthermore, mechanical property of the PAr/DPAr was higher than that of the PAr itself, probably due to partial crosslinking induced by carbene species generated from DNQ during heating.

Keyword: polyarylate, diazonaphthoquinone (DNQ), reaction development patterning (RDP), DNQ-introduced polyarylate (DPAr)
\end{abstract}

\section{Introduction}

Photo-irradiation onto a photosensitive polymer film induces change in solubility to a developer, and micro- and nano-patterns can be easily prepared from photosensitive polymers by using this solubility change. Such fine patterns are widely used in various areas such as fabrication of integrated circuits (ICs) $[1,2]$. Photoresists used for IC patterning are required to have good lithographic properties like high sensitivity, resolution and resistance to etching, but their thermal and mechanical properties are of slight importance because photoresists are usually removed after the desired IC patterns are obtained. On the other hand, in the production of buffer coat layers, interlayer dielectric films, optical waveguides, etc, the patterned photosensitive polymers remain in the devices, and therefore, they are required to have high thermal, mechanical and electrical insulating properties in addition to photosensitivity. To satisfy these properties, photosensitive polyimides (PSPIs) have been studied $[3,4]$. Polyimides are representative engineering plastics with good thermal, mechanical and electrical properties and addition of photosensitivity to polyimides enables photolithographic preparation of polyimide patterns. Conventional PSPIs have functional groups to add photosensitivity in the polymer structure. For example, representative negative-type PSPIs 
have acryl of methacryl groups to crosslink their chains when the polymers are photoirradiated, and positive-type PSPIs are usually composed of poly(amic acid) derivatives or polyimides with hydrophilic functional groups in order to add solubility to aqueous alkaline solution. However, such functional groups in PSPIs not only increase complexity of synthetic process but also decrease physical and chemical stability of the polyimides.

Recently, we have developed a novel pattern-forming method, reaction development patterning (RDP), which can add photosensitivity to engineering plastics having carboxylic-acid-derivative $(-\mathrm{C}(\mathrm{O})-\mathrm{X}-)$ bonds in the main chain. RDP gives positive-tone patterns by photo-irradiation to films of engineering plastics containing diazonaphthoquinone (DNQ) as a photosensitive agent and the following development with a solution containing nucleophile like ethanolamine (EA). Pattern formation by RDP is based on decrease in molecular weight induced by nucleophilic acyl substitution between $-\mathrm{C}(\mathrm{O})-\mathrm{X}$ - bonds in the polymers and nucleophile in the developer, and preferential permeation of the developer into the photoirradiated areas is achieved by acid generated from DNQ by photo-irradiation (Figure 1). RDP uses inherent - $\mathrm{C}(\mathrm{O})-\mathrm{X}$ - bonds in engineering plastics for pattern formation, and therefore, a variety of engineering plastics including commercially available poly(ether imide), polycarbonate, and polyarylate (PAr) can be used as the polymer component of RDP without introducing additional functional groups [5-21].

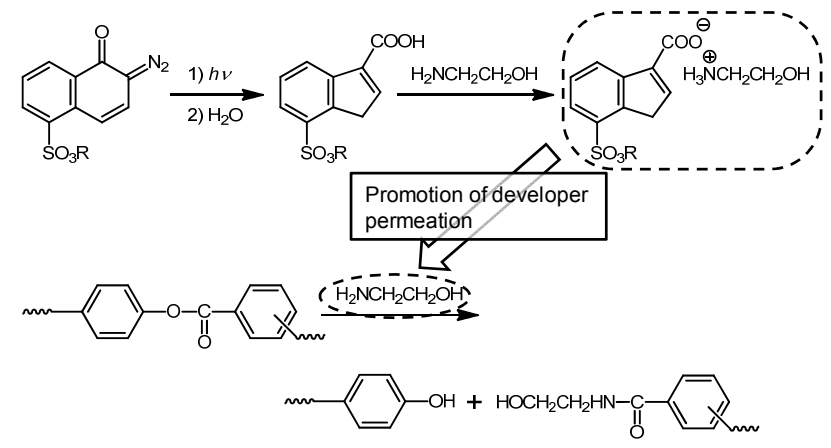

Figure 1. Patter-forming mechanism of positive- tone photosensitive PAr based on RDP

Though RDP is useful and versatile method, it has a problem for practical applications that properties of the prepared patterns are de- creased in comparison with the original polymers due to the presence of low-molecularweight photosensitive agents. Therefore, in this study, we have developed RDP-based photosensitive polymers not containing lowmolecular-weight photosensitive agents but using polymers having covalently introduced DNQ groups in their polymer chains. We have chosen PArs as the target polymers because DNQ-introduced PArs (DPArs) can be easily prepared by polycondensation between terephthaloyl chloride / isophthaloyl chloride mixture and a bisphenol-type DNQ monomer. RDP-based pattern formation was then applied to a series of the obtained DPArs and lithographic properties were compared with the conventional RDP-based photosensitive PAr containing low-molecular-weight DNQ. Utilization of DPArs as photosensitive additives instead of low-molecular-weight DNQ was also examined. Furthermore, thermal and mechanical properties of the DPAr and PAr/DPAr films were investigated.

\section{Experimental}

\subsection{Materials}

Reagents were obtained from Tokyo Chemical Industry, Co., Ltd., Wako Pure Chemical Industries, Ltd., and Sigma-Aldrich Co. LLC. and used without further purification unless otherwise noted. 1,2-Naphthoquinonediazide 5 -sulfonic acid $p$-cresol ester (PC-5) and BADNQ1 (Scheme 1) were kindly donated from Toyo Gosei Co., Ltd. and Sanbo Chemical Ind. Co., Ltd. Polyarylate (U polymer ${ }^{\circledR}$ ) was kindly donated from Unitika Ltd. 1,2Dichloroethane (anhydrous, 99.8\%) was purchased from Sigma-Aldrich Co. LLC. and triethylamine was distilled from calcium hydride $\left(\mathrm{CaH}_{2}\right)$.

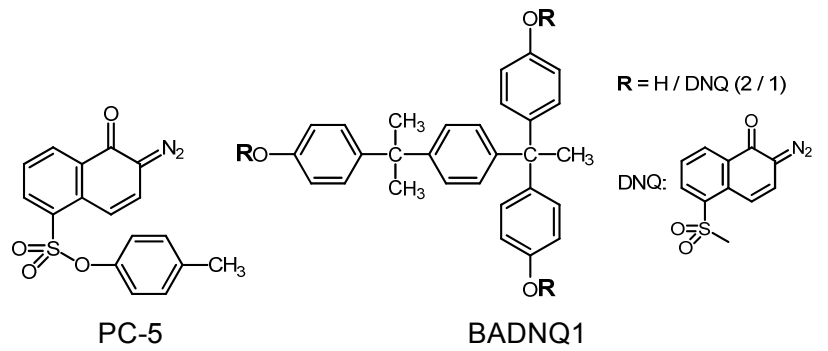

Scheme 1

\subsection{Measurements}

${ }^{1} \mathrm{H}-\mathrm{NMR}$ spectra were recorded on a BRUKER DRX300 spectrometer $(300 \mathrm{MHz})$ 
at room temperature using chloroform- $d$ as a solvent and tetramethylsilane as an internal standard. Molecular weight was determined by gel permeation chromatography (GPC) (Tosoh TSKgel $\mathrm{GMH}_{\mathrm{HR}}-\mathrm{M}$ column, polystyrene standards) equipped with RI detector (Tosoh, RI-8021) with DMF containing $\mathrm{LiBr}$ $(30 \mathrm{mmol} / \mathrm{L})$ and phosphoric acid $(60 \mathrm{mmol} / \mathrm{L})$ as an eluate (eluting rate: $1.0 \mathrm{~mL} / \mathrm{min}$ ). Thermogravimetric analysis (TGA) was carried out by using DTG-60 (Shimadzu) in the temperature range between 30 and $800{ }^{\circ} \mathrm{C}$ at $10{ }^{\circ} \mathrm{C} / \mathrm{min}$ under $\mathrm{N}_{2}$. Dynamic mechanical analysis (DMA) was performed on DMS-6100 (SII Nanotechnology) in tensile mode using dynamic frequency of $1 \mathrm{~Hz}$, and measurements were carried out by heating rate of $5{ }^{\circ} \mathrm{C} / \mathrm{min}$ under air. Infrared (IR) spectra were recorded using a Perkin Elmer SPECTRUM ONE spectrometer and $\mathrm{KBr}$ pellet method. Film thickness was measured using a contact-type thickness analyzer (Nikon, DIGIMICRO MFC101). Photo-irradiation was carried out with a UV exposure apparatus equipped with ultra high-pressure mercury lamp (ORC Manufacturing, JP-2000-EXC) and the exposure dose was measured in the $320-390 \mathrm{~nm}$ range with an ORC UV-331AP2 (ORC Manufacturing Co., Ltd). Scanning electron micrograph (SEM) was obtained with JEOL JSM-6390LV.

\subsection{Synthesis of DNQ-introduced polyaryl- ates (DPArs)}

A typical procedure for synthesis of DPAr1 (Table 1) is as follows: Into a $200 \mathrm{~mL}$ fournecked flask with magnetic stirring bar, 1.66 g (7.27 mmol) of bisphenol A (BPA) and 1.79 $\mathrm{g}(2.73 \mathrm{mmol})$ of BADNQ1 were added, and the flask was degassed by vacuum / $\mathrm{N}_{2}$ substitution for five times. Then, $25 \mathrm{~mL}$ of 1,2dichloroethane and $3.3 \mathrm{~mL}(24 \mathrm{mmol}: 1.2 \mathrm{eq}$. for phenol groups) of triethylamine were added, and the mixture was stirred. After solid was dissolved, $1.97 \mathrm{~g}(9.70 \mathrm{mmol})$ of $1: 1$ mixture of terephthaloyl chloride and isophthaloyl chloride in 1,2-dichloroethane (20 $\mathrm{mL}$ ) was added, and the flask was immersed in an ice bath for $2 \mathrm{~h}$. The reaction mixture was then diluted with chloroform and the precipitated triethylammonium chloride was removed by decantation. The supernatant was poured into acetone/methanol mixture (1/1 $(\mathrm{v} / \mathrm{v}))$. The precipitate was collected by filtra- tion and dried under vacuum overnight at $40{ }^{\circ} \mathrm{C}$.

In the case of preparation of DPAr 1, 3 and 5 , the products were dissolved in NMP at $70{ }^{\circ} \mathrm{C}$ and insoluble fraction was removed by filtration. The obtained solution was poured into acetone/methanol solution $(1 / 1(\mathrm{v} / \mathrm{v}))$ and the precipitate was collected by the same procedure as described above to give the products.

\subsection{Pattern formation from DPAr films}

17 or $25 \mathrm{wt} \%$ of DPAr was dissolved in NMP at $70{ }^{\circ} \mathrm{C}$, and the solution was degassed and spin-coated onto mat side of a copper foil and prebaked at $90{ }^{\circ} \mathrm{C}$ for $10 \mathrm{~min}$. The obtained film was irradiated with an ultra highpressure mercury lamp $\left(1000 \mathrm{~mJ} / \mathrm{cm}^{2}\right)$ without any filter at both the $\mathrm{i}$ and $\mathrm{g}$ lines through a positive photomask in a contact technique. The exposed film was developed with $\mathrm{EA} / \mathrm{NMP} / \mathrm{H}_{2} \mathrm{O}=4 / 1 / 1(\mathrm{w} / \mathrm{w} / \mathrm{w})$ solution at 40-45 ${ }^{\circ} \mathrm{C}$ under ultrasonication and rinsed with $\mathrm{H}_{2} \mathrm{O}$.

2.5. Pattern formation from PAr films containing DPArs as photosensitive agents

15 or $25 \mathrm{wt} \%$ of PAr solution was prepared by dissolving PAr into NMP at $70{ }^{\circ} \mathrm{C}$. The solution was then cooled to room temperature and DPAr was added. The amount of DPAr was determined to become the ratio of DNQ moiety in the polymers to be 13 or $20 \mathrm{wt} \%$. The resulting solution was spin-coated, irradiated and developed according to the same procedure as described in the section 2.4.

2.6. Preparation of samples for DMA measurements

$15 \mathrm{wt} \%$ solution of PAr, PAr/PC-5 or PAr/DPAr in chloroform was spin-coated onto a PET film and baked at $30{ }^{\circ} \mathrm{C} / 10 \mathrm{~min}+60{ }^{\circ} \mathrm{C} / 1 \mathrm{~h}+160{ }^{\circ} \mathrm{C} / 2 \mathrm{~h}$. The obtained film was then peeled off from the PET film and used for DMA measurement.

\section{Results and Discussion}

3.1. Preparation of DNQ-introduced PArs (DPArs)

DPArs with various molecular weights and DNQ contents were synthesized by solution polycondensation between terephthaloyl chloride / isophthaloyl chloride mixture and BPA / BADNQ1 mixture or BADNQ1 (Scheme 2). 


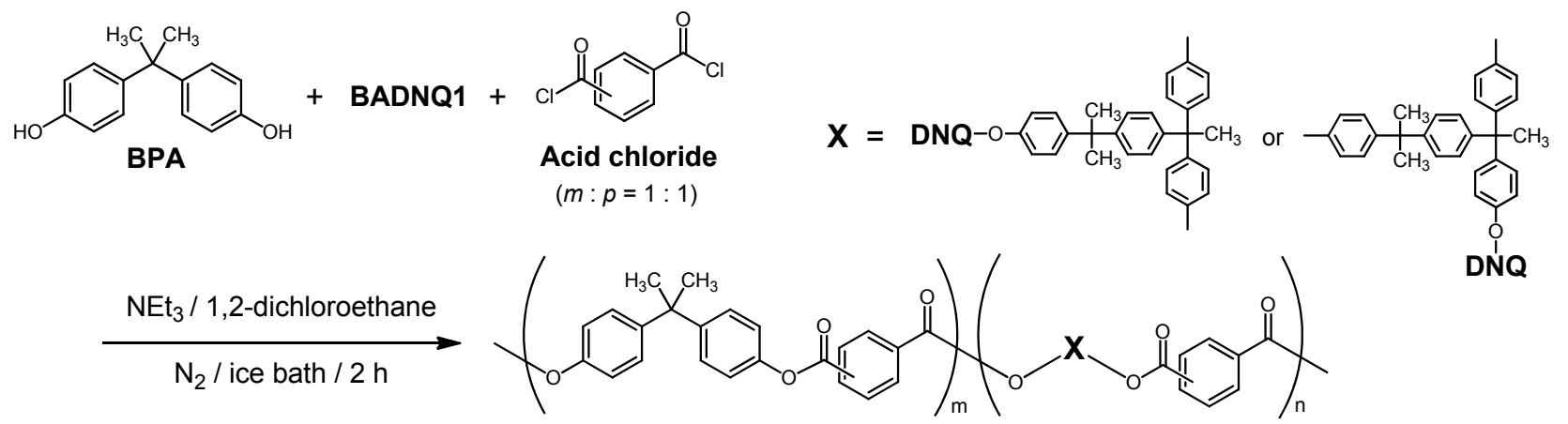

DNQ-introduced PAr (DPAr)

Scheme 2

The results of synthesis are summarized in Table 1. In this study, NMP was used as a solvent for film formation. Therefore, when a product was partially insoluble in NMP, the NMP-insoluble fraction was removed by filtration and the isolated soluble part was considered to be a final product. In DPAr1 and 2, BPA was used as a non-photosensitive monomer to adjust DNQ contents in the polymers. DPArs satisfying both high DNQ content and high molecular weight could not be obtained because theoretical maximum DNQ content is limited to $32 \mathrm{wt} \%$ and high-molecular-weight products were insoluble in NMP. This insolubility would be derived from branched (or partially cross-linked) structure of the DPArs induced by triphenol present in BADNQ1 as a byproduct (Scheme 3 ). The presence of branching in DPArs with high DNQ content is supported by high polydispersity indices (PDI) of DPArs 3-5 (Table 1).

The structure of the products was confirmed by ${ }^{1} \mathrm{H}$-NMR spectroscopy, GPC and IR spectroscopy. A typical example of a ${ }^{1} \mathrm{H}-\mathrm{NMR}$ spectrum of DPAr (DPAr4 in Table 1) is shown in Figure 2, and the DNQ content was calculated from the peak area ratio between<smiles>CC(C)(c1ccc(O)cc1)c1ccc(C(C)(c2ccc(O)cc2)c2ccc(O)cc2)cc1</smiles>

Scheme 3

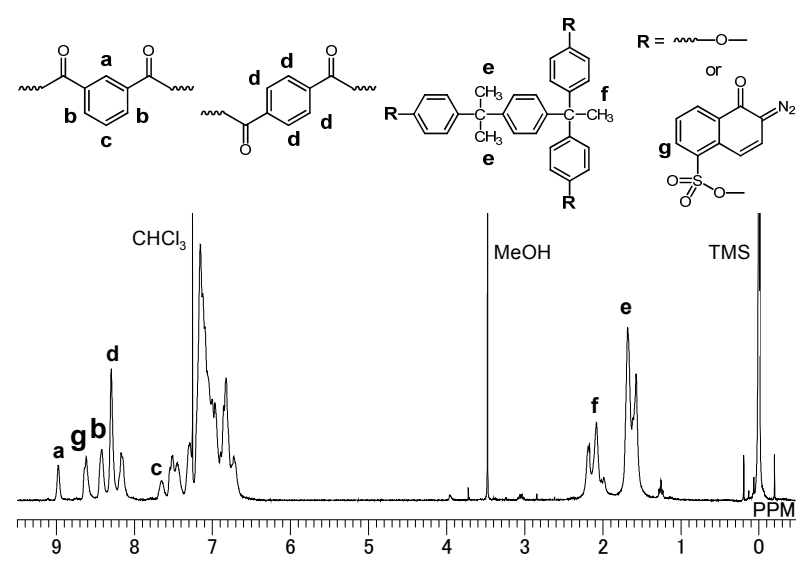

Figure 2. ${ }^{1} \mathrm{H}-\mathrm{NMR}$ spectrum of DPAr4 $\left(\mathrm{CDCl}_{3}\right)$

Table 1 Results of synthesis of DPArs

\begin{tabular}{|c|c|c|c|c|c|c|c|}
\hline Polymer & $\begin{array}{l}\text { BPA / BADNQ1 / Chloride } \\
\text { (molar ratio in feed) }\end{array}$ & $\begin{array}{l}\text { Yield } \\
{[\%]}\end{array}$ & $M_{\mathrm{n}}{ }^{1)} \times 10^{4}$ & $M_{\mathrm{w}}{ }^{1)} \times 10^{4}$ & $P D I^{1)}$ & $m: n^{2)}$ & $\begin{array}{l}\text { DNQ content } \\
{[\mathrm{wt} \%]^{2)}}\end{array}$ \\
\hline DPAr1* & $7.27 / 2.73 / 9.7$ & 36 & 2.1 & 6.0 & 2.8 & $0.80: 0.20$ & 13 \\
\hline DPAr2 & 7.4 / 2.6 / 8.6 & 62 & 1.2 & 2.8 & 2.3 & $0.78: 0.22$ & 12 \\
\hline DPAr3* & $0 / 10 / 8.6$ & 48 & 0.98 & 5.8 & 5.9 & $0: 1.0$ & 29 \\
\hline DPAr4 & $0 / 10 / 8.0$ & 69 & 1.3 & 6.3 & 5.0 & $0: 1.0$ & 29 \\
\hline DPAr5* & $0 / 10 / 7.5$ & 54 & 0.95 & 4.9 & 5.2 & $0: 1.0$ & 29 \\
\hline
\end{tabular}

1) By GPC (DMF, polystyrene standard, detected by RI)

2) Calculated by ${ }^{1} \mathrm{H}-\mathrm{NMR}$

* Soluble fraction in NMP was defined as a product. 
the peaks $b$ and $g$. IR spectrum of DPAr4 was also shown in Figure 3, and a characteristic peak derived from a diazo group in DNQ was observed around $2000-2200 \mathrm{~cm}^{-1}$. This indicates that DNQ groups were not inactivated during polymer synthesis and DPArs were successfully prepared.

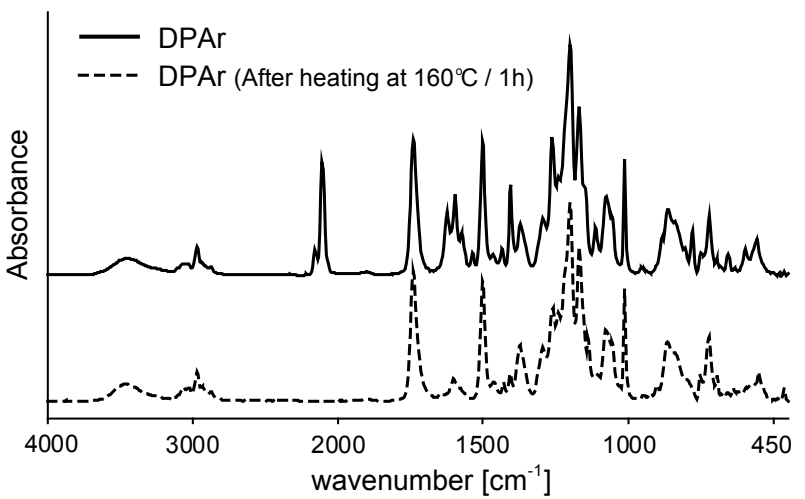

Figure 3. IR spectra of DPAr4 (solid line) and DPAr4 heated at $160{ }^{\circ} \mathrm{C}$ for $1 \mathrm{~h}$ (dashed line)

\subsection{Pattern formation from DPAr films}

Positive-tone RDP was applied to the synthesized DPArs. Development conditions of DPArs were determined according to those of the photosensitive PAr using PC-5 as a low-molecular-weight photosensitive agent (PAr/PC-5 system) [8,11]. The DPAr films prepared by spin-coating of their NMP solution on copper foils were irradiated through a photomask and then developed by EA/NMP/ $\mathrm{H}_{2} \mathrm{O}=4 / 1 / 1$ solution. As a result, all DPAr films afforded fine positive-tone patterns (Table 2, Figure 3).

It was suggested that the development properties of DPArs were affected by DNQ content, molecular weight and PDI of the polymers. Increase in DNQ content and de- crease in molecular weight realized shorter development time and higher resolution. On the other hand, DPAr3 afforded fine patterns in much shorter development time than DPAr5 in spite of their almost the same molecular weights. These results would be attributed to higher PDI of DPAr3 than that of DPAr5. The value of PDI is an indication of the degree of branching, and more branched structure of DPAr3 would increase free volume in the polymer film. This would promote permeation of the developer into the film and result in pattern formation in shorter development time than DPAr5.

As shown in Table 2, the development times of DPAr systems were shorter than those of PAr/PC-5 systems when the systems of almost the same DNQ contents were compared. The dissolution rates of the exposed and unexposed areas in positive-tone RDP of DPAr and PAr/PC-5 films are summarized in Figure 4. From the table and figure, it is obvious that better development properties of DPArs than the conventional PAr/PC-5 is derived from significant improvement in dissolution rate at the exposed areas. Also, as described above, the systems with larger PDI values (DPArs 3 and 4) showed very fast dissolution of the exposed areas.

In order to elucidate the effect of branched structure in the polymers on dissolution, we applied RDP to a branched polyarylate without DNQ structure in the polymer chain (= bulky PAr in Figure 4). The bulky PAr was synthesized by solution polycondensation between terephthaloyl/isophthaloyl chlorides, BPA and the triphenol (Scheme 3) with the feed ratio of 9.0:8.6:1.4. As a result of application of RDP, the film of the bulky PAr

Table 2 Results of pattern formation from DPAr films ${ }^{1)}$

\begin{tabular}{|c|c|c|c|c|c|c|c|c|c|c|}
\hline \multirow{2}{*}{ Polymer } & \multirow{2}{*}{$M_{\mathrm{n}} \times 10^{4}$} & \multirow{2}{*}{ PDI } & \multirow{2}{*}{ Additive } & \multirow{2}{*}{$\begin{array}{l}\text { DNQ content } \\
{[w t \%]}\end{array}$} & \multirow{2}{*}{$\begin{array}{l}\text { Development } \\
\text { [min'sec] }\end{array}$} & \multirow{2}{*}{$\begin{array}{c}\text { Thickness }^{2,3)} \\
{[\mu \mathrm{m}]}\end{array}$} & \multicolumn{2}{|c|}{ Dissolution rate $[\mathrm{nm} / \mathrm{s}]$} & \multirow{2}{*}{$\begin{array}{c}\text { Residual }^{3)} \\
{[-]}\end{array}$} & \multirow{2}{*}{$\begin{array}{c}\text { Resolution }^{4)} \\
{[\mu \mathrm{m}]}\end{array}$} \\
\hline & & & & & & & Exposed & Unexposed & & \\
\hline DPAr1 & 2.1 & 2.8 & - & 13 & $15^{\prime} 44$ & $7.0 \rightarrow 5.8$ & 7.4 & 1.3 & 0.83 & 25 \\
\hline DPAr2 & 1.2 & 2.3 & - & 12 & 13 '05 & $7.0 \rightarrow 6.7$ & 8.9 & 0.38 & 0.90 & 15 \\
\hline DPAr4 & 1.3 & 4.8 & - & 29 & $10 ' 36$ & $11.2 \rightarrow 10.8$ & 18 & 0.63 & 0.96 & 10 \\
\hline DPAr5 & 0.95 & 5.2 & - & 29 & $4^{\prime} 50$ & $6.7 \rightarrow 6.3$ & 23 & 1.4 & 0.94 & 10 \\
\hline DPAr3 & 0.98 & 5.9 & - & 29 & $2 ' 32$ & $6.2 \rightarrow 5.9$ & 41 & 2.0 & 0.95 & 10 \\
\hline \multirow{2}{*}{$\mathrm{PAr}^{*}$} & \multirow{2}{*}{2.8} & \multirow{2}{*}{1.7} & \multirow{2}{*}{ PC-5 } & 13 & 45 '39 & $9.6 \rightarrow 6.8$ & 3.5 & 1.0 & 0.71 & 30 \\
\hline & & & & 30 & $18^{\prime} 00$ & $11.2 \rightarrow 10.2$ & 10 & 0.93 & 0.91 & 15 \\
\hline
\end{tabular}

1) Exposure dose: $1000 \mathrm{~mJ} / \mathrm{cm}^{2}$, Developer: EANMP/ $\mathrm{H}_{2} \mathrm{O}=4 / 1 / 1(\mathrm{w} / \mathrm{w} / \mathrm{w})$, Development condition: $40-45^{\circ} \mathrm{C} /$ ultrasonication

$\begin{array}{llll}2) & \text { By contact-type thicknessmeter } & \text { 3) At unexposed area } & \text { 4) Confirmed by SEM }\end{array}$

* Conventional photosensitive PAr film containing a low-molecular-weight photosensitive agent. 


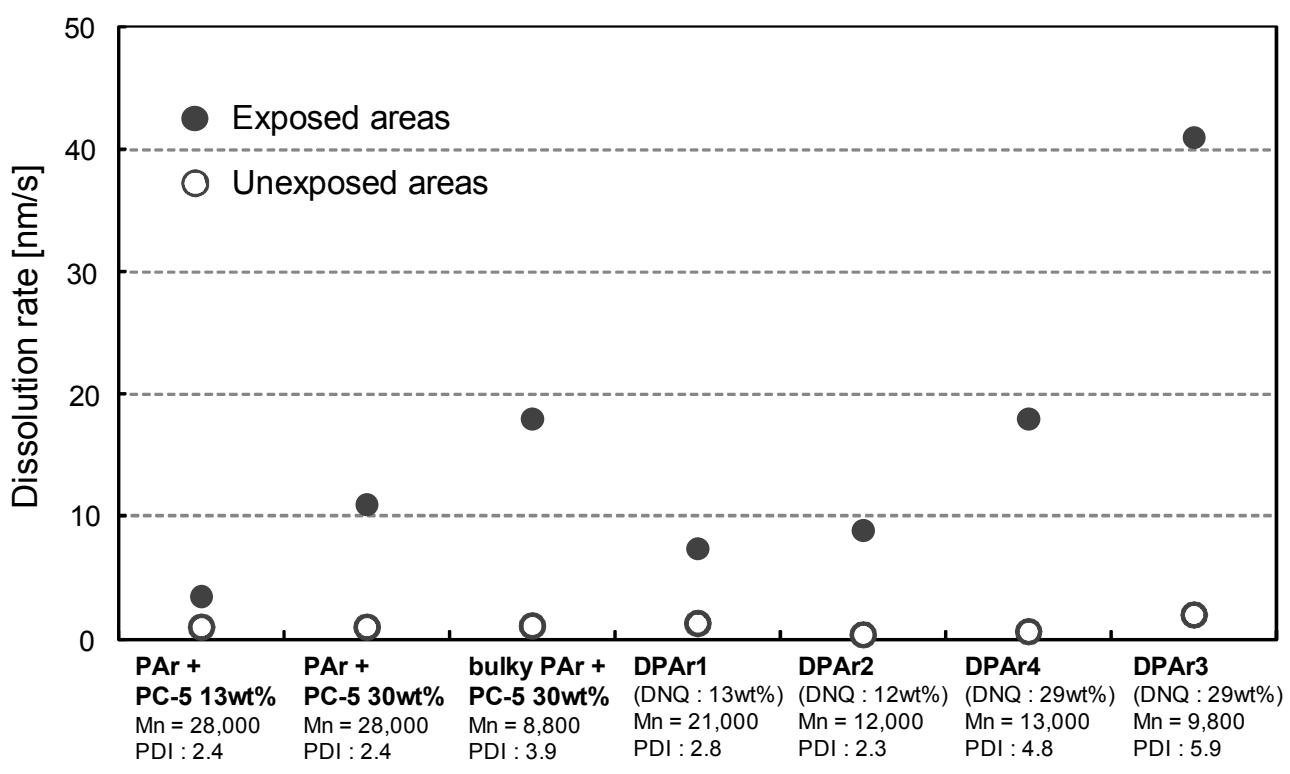

Figure 4. Dissolution rates at exposed and unexposed areas of PAr/PC-5 and DPAr films

containing PC-5 showed much higher dissolution rate at the exposed areas than the conventional PAr/PC-5 (Figure 4). This indicates that branching in the polymers derived from BADNQ1 is a reason for fast dissolution of photo-irradiated areas of DPArs.

We also carried out homogeneous model reactions between the polyarylates and EA in order to reveal the effect of reactivity between ester group in the polymers and EA on development property. 10 eq of EA to ester group in the polymers was added to $0.5 \mathrm{wt} \%$ NMP solutions of PAr, DPAr5 and photoirradiated DPAr5, and change in molecular weight of the polymers was followed by GPC. The results are shown in Figure 5, and decrease in $M_{\mathrm{n}}$ of the photo-irradiated DPAr was found to be faster than PAr at the early stage of the reaction. This indicates the photoirradiated DPAr has higher reactivity than PAr probably because DNQ groups on the polymer chain of DPArs generate acids by photoirradiation and these acids would concentrate EA around the polymer chain and promote the reaction between EA and polymer chain by so-called polymer effect. On the other hand, unexposed DPAr showed lower reactivity with EA than PAr because of the presence of bulky and hydrophobic BADNQ1 groups. These higher and lower reactivities of the photoirradiated and unirradiated DPArs, repectively, would also be reasons for shorter development time and better resolution of RDP-based photosensitive DPAr systems than those of
$\mathrm{PAr} / \mathrm{PC}-5$.

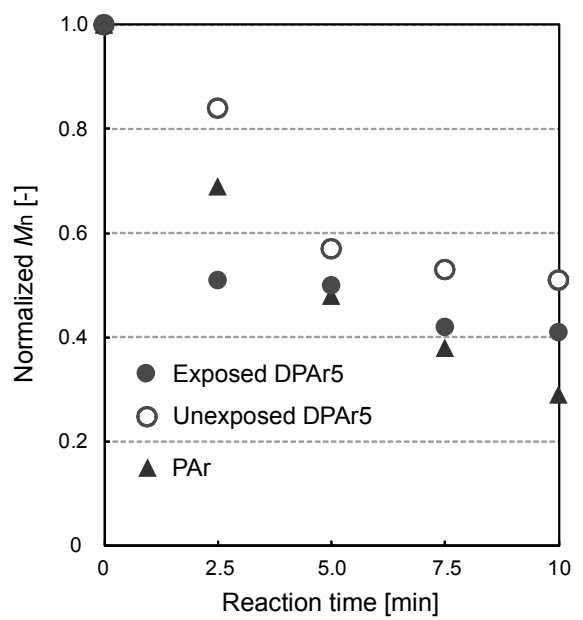

Figure 5. Relationship between reaction time and $M_{\mathrm{n}}$ in the homogeneous model reactions between the polyarylates and EA in NMP

3.3. Utilization of DPArs as high-molecular-weight photosensitive agents for RDP

In the previous section, DPArs are found to be the polymers combining functions as matrix polymers with photosensitive agents for RDP. However, introduction of DNQ structure into the polymer chains of PArs is considered to decrease properties of DPArs as engineering plastics when compared to PAr itself (see the section 3.5.). This disadvantage of DPArs is expected to be minimized when DPArs are used not as matrix polymers but as high-molecular-weight photosensitive agents. Therefore, we applied positive-tone RDP to PAr films containing DPArs as the high-molecularweight photosensitive agents. 
Table 3 Results of pattern formation from photosensitive PAr films ${ }^{1)}$

\begin{tabular}{|c|c|c|c|c|c|c|c|c|c|}
\hline \multirow{2}{*}{ Entry } & \multicolumn{3}{|c|}{ Photosensitive agent } & \multirow{2}{*}{$\begin{array}{l}\text { Development } \\
\text { [min'sec] }\end{array}$} & \multirow{2}{*}{$\begin{array}{c}\text { Thickness }^{3,4)} \\
{[\mu \mathrm{m}]}\end{array}$} & \multicolumn{2}{|c|}{ Dissolution rate $[\mathrm{nm} / \mathrm{s}]$} & \multirow{2}{*}{$\begin{array}{l}\text { Residual }^{4)} \\
{[-]}\end{array}$} & \multirow{2}{*}{$\begin{array}{c}\text { Resolution } \\
{[\mu \mathrm{m}]}\end{array}$} \\
\hline & name & $M_{\mathrm{n}} \times 10^{4}$ & content $^{2)}[w t \%]$ & & & Exposed & Unexposed & & \\
\hline 1 & DPAr4 & 1.3 & 20 & 8'06 & $10.6 \rightarrow 10.1$ & 22 & 1.0 & 0.95 & 10 \\
\hline 2 & DPAr5 & 0.95 & 20 & $12 ' 35$ & $10.0 \rightarrow 9.6$ & 13 & 0.53 & 0.96 & 10 \\
\hline 3 & DPAr3 & 0.98 & 20 & 9'38 & $8.9 \rightarrow 8.8$ & 15 & 0.17 & 0.99 & 10 \\
\hline 4 & DPAr3 & 0.98 & 13 & $22 ' 42$ & $8.7 \rightarrow 7.9$ & 6.4 & 0.59 & 0.91 & 10 \\
\hline $5^{*}$ & PC-5 & - & 13 & $45^{\prime} 32$ & $9.6 \rightarrow 6.8$ & 3.5 & 1.0 & 0.71 & 30 \\
\hline
\end{tabular}

1) Exposure dose: $1000 \mathrm{~mJ} / \mathrm{cm}^{2}$, Developer: EA/NMP/ $\mathrm{H}_{2} \mathrm{O}=4 / 1 / 1$ (w/w/w), Development condition: $40-45^{\circ} \mathrm{C} /$ ultrasonication
2) In the prepared films
3) By contact-type thicknessmeter
4) At unexposed area
5) Confirmed by SEM

* Conventional photosensitive PAr film containing a low-molecular-weight photosensitive agent

The results of pattern formation from PAr films containing DPArs (PAr/DPAr systems) are summarized in Table 3. All systems afforded fine positivetone patterns (see Figure 6a) and this indicates that DPArs can be used as photosensitive agents for positive-tone RDP. In addition, pattern formation from the PAr/DPAr system with $13 \mathrm{wt} \%$ DNQ (entry 4) was achieved in half development time of that from the PAr/PC-5 system with the same DNQ content (entry 5). This means that PAr/DPAr systems have better development properties than the conventional PAr/PC-5 system.

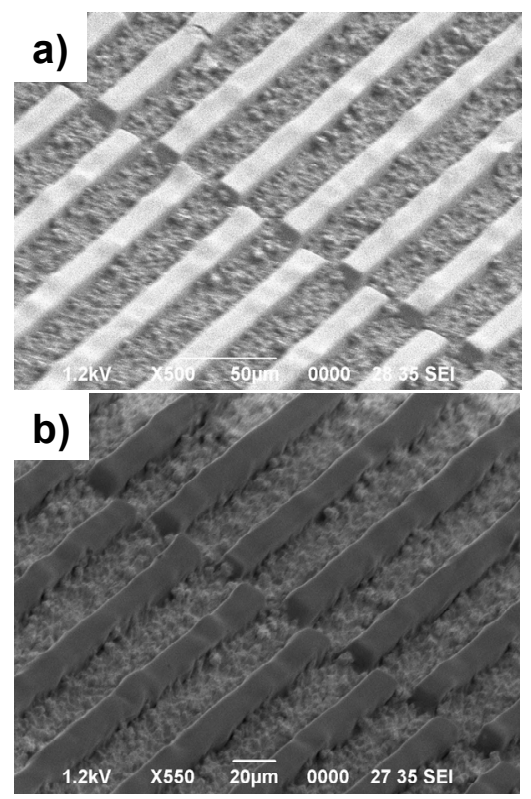

Figure 6. SEM images of $20 \mu \mathrm{m}$ line and space patterns from PAr / DPAr5 (entry 2 in Table 3)

a) as-prepared pattern, b) after heat treatment at $210{ }^{\circ} \mathrm{C}$ for $1 \mathrm{~h}$

3.4. Thermal and mechanical properties of RDPbased photosensitive polymers

Thermal stability of DPArs was investigated by TGA measurement. As a typical example, TGA chart of DPAr4 (Table 1) is shown in Figure 7. All DPArs showed slight weight loss around 115-
$160{ }^{\circ} \mathrm{C}$, and the weight loss of DPAr4 at this temperature range was $3.15 \mathrm{wt} \%$. These weight loss behaviors are similar to that of BADNQ1, and therefore, would be attributed to BADNQ1 structure in the polymers. Thus, DPAr4 was heated at $160{ }^{\circ} \mathrm{C}$ for $1 \mathrm{~h}$ on a hot plate and the structure of the obtained product was investigated by IR spectroscopy (Figure 3). As a result, disappearance of the peak derived from diazo group around 2,000 $\mathrm{cm}^{-1}$ was confirmed, and the weight loss in TGA is also identified as degradation of diazo group in DPAr.

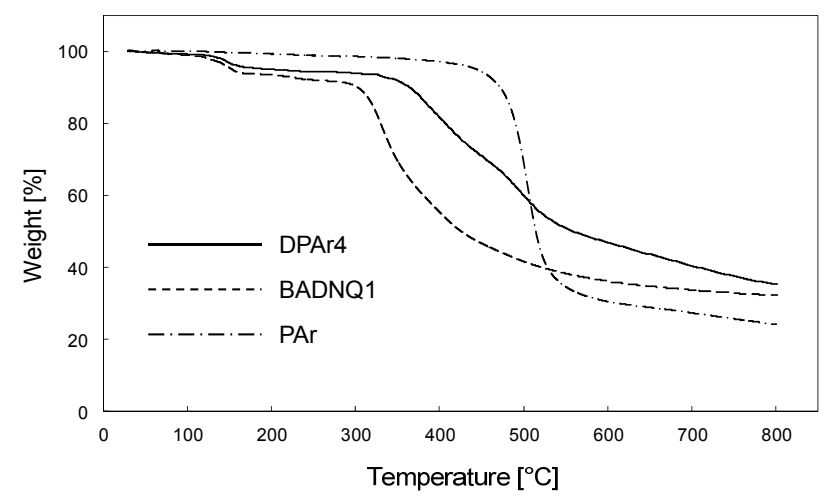

Figure 7. TGA charts of DPAr4, BADNQ1 and PAr $\left(10^{\circ} \mathrm{C} / \mathrm{min}\right.$ under $\left.\mathrm{N}_{2}\right)$

These results suggest that prior-to-use heat treatment of patterns containing DPArs is important to exert their performances as engineering plastics. Thus, we applied heat treatment at $210^{\circ} \mathrm{C}$ for $1 \mathrm{~h}$ to the patterns prepared from PAr/DPAr5 film (Table 3, entry 2). The heat treatment condition was determined to remove diazo group and residual solvent in the patterns completely. The heat-treated patterns showed slight decrease in film thickness (from 9.6 to $8.8 \mu \mathrm{m}$ ) and width (from 13.8 to $12.5 \mu \mathrm{m}$ ), but the shape of the patterns was maintained after the heat treatment (Figure 6b).

Furthermore, we investigated thermal and mechanical properties of the heat-treated films by TGA and DMA. TGA charts of PAr/DPAr5 and 
PAr/PC-5 films are shown in Figure 8, and no weight loss at low temperature region was observed. Char yield of PAr/DPAr5 at $800{ }^{\circ} \mathrm{C}$ was higher than PAr/PC-5 by ca. $10 \%$. DMA charts of the PAr/DPAr5, PAr/PC-5 and neat PAr films are shown in Figure 9. The DMA charts revealed that the PAr/PC-5 showed significant decrease in glass transition temperature $\left(T_{\mathrm{g}}\right)$ compared with that of neat PAr (PAr/PC-5: $169^{\circ} \mathrm{C}$, neat PAr: $\left.220^{\circ} \mathrm{C}\right)$. On the other hand, PAr/DPAr showed almost the same $T_{\mathrm{g}}$ as neat PAr. Moreover, PAr/DPAr exhibited unusual behavior that it kept high storage modulus even at rubber state, while PAr/PC-5 and neat PAr showed typical thermoplastic behaviors at high temperature regions. The maintenance of storage modulus in PAr/DPAr would be derived from partial cross-linking induced by highly reactive carbene species generated by elimination of diazo groups. Therefore, patterns prepared from PAr/DPAr by RDP are also expected to have much better thermal and mechanical properties than those from the conventional PAr/PC-5.

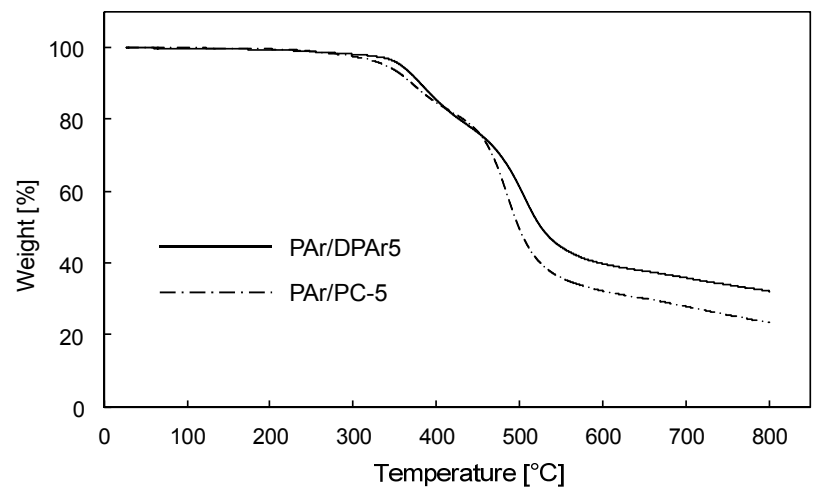

Figure 8. TGA charts of heat-treated PAr/DPAr5 and PAr/PC-5 $\left(10^{\circ} \mathrm{C} / \mathrm{min}\right.$ under $\left.\mathrm{N}_{2}\right)$

\section{Conclusion}

A series of DNQ-introduced PArs (DPArs) were synthesized by polycondensation using BADNQ1 as a diphenol component. Application of RDP to DPArs gave fine positive-tone patterns without addition of low-molecularweight photosensitive agents. Utilization of DPArs as high-molecular-weight photosensitive agents for RDP-based photosensitive PAr systems was also examined and resulted in successful positive-tone pattern formation in shorter development time and higher resolution than conventional PAr with low-molecular-weight photosensitive agent system. It was revealed that the excellent development properties of DPAr systems were attributed to the

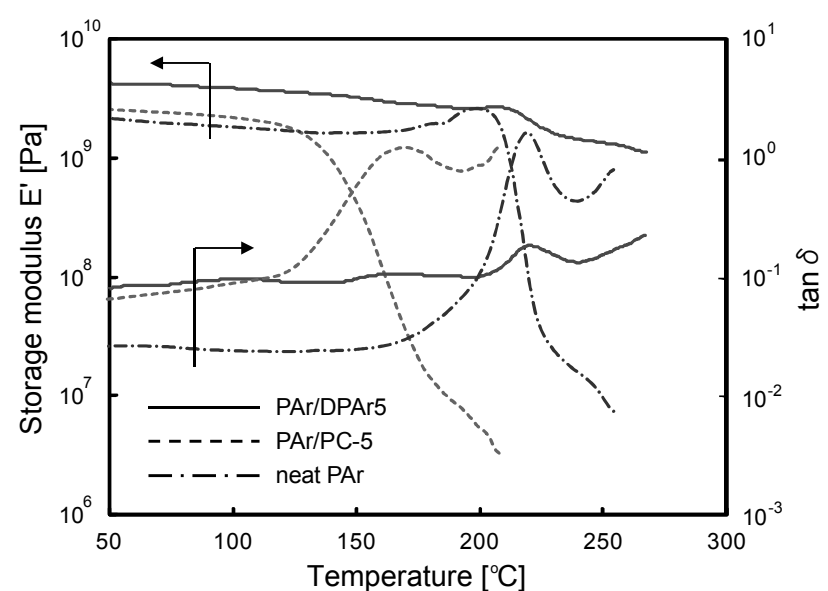

Figure 9. DMA charts of heat-treated PAr/DPAr5, PAr/PC-5 and neat PAr $\left(5{ }^{\circ} \mathrm{C} / \mathrm{min}\right.$ under air $)$

improvement in dissolution rate at photoirradiated areas derived from branched polymer structures induced by triphenol byproduct in BADNQ1 and high reactivity between photo-irradiated DPAr and EA. In addition, the PAr/DPAr films showed better thermal and mechanical properties than the conventional PAr with low-molecular-weight DNQ film.

\section{References}

1. "Polymers for Microelectronics and Nanoelectronics", Q. Lin, R. A. Pearson, J. C. Hedrick Eds., ACS Symposium Series 874, American Chemical Society: Washington DC, 2004.

2. "Micro- and Nanopatterning Polymers", $\mathrm{H}$. Ito, ACS Symposium Series 706, American Chemical Society: Washington DC, 1998.

3. R. Rubner, H. Ahne, E. Kuhn, G. Koloddieg, Photograph. Sci. Eng., 23 (1979) 303.

4. K. Fukukawa, M. Ueda, Polym. J., 40 (2008) 281.

5. T. Fukushima, T. Oyama, T. Iijima, M. Tomoi, H. Itatani, J. Polym. Sci. Part A : Polym. Chem., 39 (2001) 3451.

6. T. Oyama, Y. Kawakami, T. Fukushima, T. Iijima, M. Tomoi, Polym. Bull., 47 (2001) 175.

7. T. Fukushima, Y. Kawakami, T. Oyama, M. Tomoi, J. Photopolym. Sci. Technol., 15 (2002) 191.

8. T. Oyama, A. Kitamura, T. Fukushima, T. Iijima, M. Tomoi, Macromol. Rapid Commun., 23 (2002) 104.

9. T. Miyagawa, T. Fukushima, T. Oyama, T. Iijima, M. Tomoi, J. Polym. Sci. Part A : 
Polym. Chem., 41 (2003) 861.

10. T. Fukushima, Y. Kawakami, T. Oyama, T. Iijima, M. Tomoi, J. Microlith. Microfab. Microsyst., 3 (2004) 159.

11. T. Oyama, A. Kitamura, E. Sato, M. Tomoi, $J$. Polym. Sci. Part A : Polym. Chem., 44 (2006) 2694.

12. S. Sugawara, M. Tomoi, T. Oyama, Polym. J., 39 (2007) 129.

13. T. Oyama, S. Sugawara, Y. Shimizu, X. Cheng, M. Tomoi, A. Takahashi, J. Photopolym. Sci. Technol., 22 (2009) 597.

14. Y. Shimizu, A. Takahashi, T. Oyama, $J$. Photopolym. Sci. Technol., 22 (2009) 407.

15. X. Cheng, A. Takahashi, T. Oyama, Polym. J.,
$42(2010) 86$.

16. T. Oyama, Y. Shimizu, A. Takahashi, J. Photopolym. Sci. Technol., 23 (2010) 141.

17. S. Yasuda, A. Takahashi, T. Oyama, S. Yamao, J. Photopolym. Sci. Technol., 23 (2010) 511.

18. A. Kasahara, A. Takahashi, T. Oyama, $J$. Photopolym. Sci. Technol., 24 (2011) 269.

19. M. Yasuda, A. Takahashi, T. Oyama, $J$. Photopolym. Sci. Technol., 26 (2013) 357.

20. T. Kawada, A. Takahashi, T. Oyama, $J$. Photopolym. Sci. Technol., 27 (2014) 219.

21. W. M. Zhou, T. Fukushima, M. Tomoi, T. Oyama, J. Photopolym. Sci. Technol., 27 (2014) 713. 